\title{
Developing Sustainable High Strength Concrete Mixtures Using Local Materials and Recycled Concrete
}

\author{
Anthony Torres*, Alex Burkhart \\ Department of Engineering Technology, Texas State University, San Marcos, TX, USA \\ Email: *ast36@txstate.edu
}

Received 25 December 2015; accepted 26 February 2016; published 29 February 2016

Copyright (C) 2016 by authors and Scientific Research Publishing Inc.

This work is licensed under the Creative Commons Attribution International License (CC BY). http://creativecommons.org/licenses/by/4.0/

(c) (i) Open Access

\section{Abstract}

This study presents the development of high strength concrete (HSC) that has been made more sustainable by using both local materials from central Texas and recycled concrete aggregate (RCA), which has also been obtained locally. The developed mixtures were proportioned with local constituents to increase the sustainable impact of the material by reducing emissions due to shipping as well as to make HSC more affordable to a wider variety of applications. The specific constituents were: limestone, dolomite, manufactured sand (limestone), locally available Type I/II cement, silica fume, and recycled concrete aggregate, which was obtained from a local recycler which obtains their product from local demolition. Multiple variables were investigated, such as the aggregate type and size, concrete age $(7,14$, and 28 -days), the curing regimen, and the waterto-cement ratio $(\mathrm{w} / \mathrm{c})$ to optimize a HSC mixture that used local materials. This systematic development revealed that heat curing the specimens in a water bath at $50^{\circ} \mathrm{C}\left(122^{\circ} \mathrm{F}\right)$ after demolding and then dry curing at $200^{\circ} \mathrm{C}\left(392^{\circ} \mathrm{F}\right)$ two days before testing with a w/c of 0.28 at 28 -days produced the highest compressive strengths. Once an optimum HSC mixture was identified a partial replacement of the coarse aggregate with RCA was completed at $10 \%, 20 \%$, and $30 \%$. The results showed a loss in compressive strength with an increase in RCA replacement percentages, with the highest strength being approximately $93.0 \mathrm{MPa}(13,484 \mathrm{psi})$ at 28-days for the $10 \%$ RCA replacement. The lowest strength obtained from an RCA-HSC mixture was approximately 72.9 (MPa) $(10,576$ psi) at 7-days. The compressive strengths obtained from the HSC mixtures containing RCA developed in this study are comparable to HSC strengths presented in the literature. Developing this innovative material with local materials and RCA ultimately produces a novel sustainable construction material, reduces the costs, and produces mechanical performance similar to prepackaged, commercially, available construction building materials.

\footnotetext{
${ }^{*}$ Corresponding author.
} 


\title{
Keywords
}

\author{
High Strength Concrete, Sustainability, Recycled Concrete Aggregate, Local Products, Construction \\ Materials
}

\section{Introduction}

Green construction through sustainable building materials has been an important aspect in the concrete and construction field in the last decade. Using waste products in concrete production is beneficial environmentally and economically: environmentally by replacing a portion of the virgin components with waste materials and environmentally by clean disposal of waste materials. Combining these benefits with locally obtained materials ultimately increases these factors. As Texas is one of the largest producers of cement and aggregate in the nation, it is beneficial to develop a novel sustainable construction building material that utilizes locally available materials. Combining this factor with the reuse of concrete as Recycled Concrete Aggregate (RCA) can drastically increase the sustainable impact of concrete production. Reuse of concrete from demolished structures as aggregates was introduced into practice many years ago, and from the beginning it has been considered in two main environmental aspects: solving the increasing waste storage problem and protection of limited natural sources of aggregates [1]. Presently, most of the demolished concrete extracted from old structures is of relatively good quality [1]. This characteristic demonstrates the potential that recycled concrete aggregate could provide to high strength concrete.

In the past years, improvements have been occurring in concrete and construction material technology. Sustainable use of supplementary materials and revolutionary developments in chemical admixtures has facilitated improvements in the mechanical properties of concrete materials. Such mechanical properties that have drastically been impacted are the strength, density, and the modulus of concrete materials [2]. Through these developments higher strength concrete materials have emerged, known as High Strength Concrete (HSC). However, these chemical and material developments have consistently changed the definition of high strength concrete. The American Concrete Institute (ACI) has defined high-strength concrete as a concrete meeting a high strength that cannot always be achieved routinely, using conventional constituents and normal mixing, placing, and curing practice [2]. In the 1950s, concrete with a compressive strength of $34 \mathrm{MPa}$ (5000 psi) was considered high strength [2]. Today, high-strength concrete is defined as concrete with a specified compressive strength of 55 MPa (8000 psi) or higher [2]. In many markets today, concrete having a specified compressive strength in excess of $69 \mathrm{MPa}(10,000 \mathrm{psi})$ is routinely produced on a daily basis [2]. HSC itself is considered a sustainable construction building material due to the high requirement of silica fume and fly ash, both of which are waste products from other industries, which provides beneficial properties development of concrete [2]. Not only does HSC utilize a high percentage of fly ash and/or silica fume, the high strength requirement results in a higher specific strength of the material. The specific strength of a material is the ratio of the strength to its density. Since the density of HSC doesn't increase significantly to that of conventional concrete, but the strength does, the specific strength is much higher than that of conventional concrete. This aspect impacts sustainable construction through decreased transportation cost and emissions as a smaller structural member can be produced out of HSC, which will require less fuel and produce less carbon emissions during shipping.

In the present research, an attempt has been made to develop HSC mixtures with locally available materials and RCA. The material used in this study included Type I/II Portland cement, silica fume, dolomite, manufactured sand (limestone), and a High Range Water Reducing Agent (HRWRA). Factors such as the aggregate type and size, the curing regimen, the water-to-cement ratio (w/c), and age $(7,14$, and 28 -day) were investigated.

\section{Literature Review}

\subsection{Background Information}

HSC is traditionally composed of cement, coarse aggregate that is much smaller than conventional coarse aggregate $\leq 9.5$-mm (0.375-in.) [2], fine aggregate, supplemental cementitious materials (SCM) such as silica fume, fly ash, granulated ground blast furnace slag (GGBFS), and quartz powder, fibers, and HRWRA. When used in 
optimum dosages, the HRWRA reduces the water-to-cement (or water-to-cementitious) ratio while improving the workability (viscosity) of the concrete. The addition of the SCMs enhances the mechanical properties of the cement paste by producing secondary hydrates, filling voids, and enhancing rheology [3]. Due to the burgeoning large structure industry, there are more and more requirements for higher strength concrete. HSC has been in development since the mid 1950's and many researchers are still investigating the optimum and most efficient manner to produce this material [2]. However, modern construction practices are moving towards sustainable construction through lower cost and sustainable materials, therefore, HSC improvements should also be focused on becoming more sustainable and more affordable.

The Environmental Protection Agency (EPA) has estimated that approximately 58\% of landfill waste is from construction debris, which a significant portion is concrete and masonry rubble [5]. Recycling waste concrete in the production of new concrete has been investigated since the 1970's [4]-[12]. These studies report a wide variety of results concerning the impact of the RCA on the mechanical and durability properties of the new concrete. The studies have shown that the mechanical properties depend on the properties of the recycled concrete used as well as the amount used. For example, Ravindraraj [9] reported a 9\% decrease in compressive strength with a 100\% coarse aggregate replacement with RCA, whereas Yamato et al. [10] measured a 45\% decrease. Reports have shown the same for the modulus of elasticity in which Gerardu and Hendriks [11] demonstrated a 15\% decrease with a 100\% replacement, while Frondistou-Yannas [12] reported a $40 \%$ decrease at high w/c $(0.75)$ and no decrease at lower w/c (0.55). Due to the wide variation in the properties of concrete with RCA, more research is needed on the local materials used to produce the new and recycled concrete in order to better understand the combined mixture.

\subsection{Sustainability}

This study focuses on two aspects of sustainable construction building materials; local use of constituent materials and the use of recycled materials. A major concern in the production of HSC is the high cost from shipping such materials as quartz dust, steel or specialty aggregates, and fibers. Most of these constituents are often shipped long distances and internationally in many cases, which increases the cost of the material. It should also be noted that due to the chemical interaction requirements of the silica fume and cement drastically increases the cost of commercially available, prepackaged, HSC products [3]. The commercially available HSC from Ductal uses expensive materials such as ground quartz and fibers that are not traditionally available locally, which increases the cost of the final product. Therefore, the present work focuses on developing HSC mixtures using local materials so that HSC may be made more affordable to wide variety of construction applications. Using local products drastically decreases emissions associated with long shipping routes. The second focus of this study is producing HSC with the inclusion of RCA as partial replacement of virgin coarse aggregate. Replacing virgin materials used in the production of HSC with recycled materials drastically increases the sustainable impact of the material. By using discarded waste material in new construction, the strain for new, virgin, materials is slightly alleviated while also minimizing the demand for landfill space. Additionally, the Leadership in Energy and Environmental Design (LEED) provides a material credit for using building materials or products that have been extracted, harvested or recovered, as well as manufactured, within 500 miles of the project site for a minimum of $10 \%$ or $20 \%$, based on cost, of the total material's value [4]. Therefore, using both local materials that make up $100 \%$ of the concrete product and using RCA will count double for this LEED requirement.

\section{Experimental Program}

\subsection{Materials}

The final HSC mix design consisted of dolomite coarse aggregate (1.18-mm [0.0469-in.]), manufactured sand, known as "man" sand, which is crushed from limestone with a size of 0.105-mm - 0.60-mm (0.0059-in. 0.0232-in.), Type I/II cement, silica fume, recycled concrete aggregate with a size of 1.18 -mm (0.0469-in.) to match the size of the virgin coarse aggregate, and HRWRA (Master Glenium 3030 from BASF Chemicals). All constituents were obtained from local providers within a 50-mile radius of San Marcos, TX. The aggregate was obtained from local quarries and sieved in the laboratory to achieve a specific size and gradation. The coarse aggregate size was minimized and held at an individual specific size based off the literature [2] [3] [5]-[8]. Table 1 shows the grain size distribution for the fine sand. Table 2 shows the chemical compositions of the Type 
Table 1. Grain size distribution for the manufactured sand.

\begin{tabular}{ccc}
\hline Sieve No. & Sieve size, mm (in.) & Percentage passing \\
\hline 16 & $1.18(0.0469)$ & 100 \\
30 & $0.60(0.0236)$ & 42.3 \\
50 & $0.30(0.0118)$ & 0.0 \\
\hline
\end{tabular}

Table 2. Chemical composition of cement and silica fume.

\begin{tabular}{ccc}
\hline Compound & Cement & Silica Fume \\
\hline $\mathrm{SiO}_{2}$ & $21.5 \%$ & $95.8 \%$ \\
$\mathrm{Al}_{2} \mathrm{O}_{3}$ & $4.45 \%$ & $0.18 \%$ \\
$\mathrm{Fe}_{2} \mathrm{O}_{3}$ & $3.15 \%$ & $0.19 \%$ \\
$\mathrm{CaO}$ & $64.10 \%$ & $0.30 \%$ \\
$\mathrm{~K}_{2} \mathrm{O}$ & $\mathrm{NA}$ & $0.29 \%$ \\
$\mathrm{Na}_{2} \mathrm{O}$ & $0.52 \%$ (Equiv.) & $0.20 \%$ \\
$\mathrm{MgO}$ & $1.90 \%$ & $0.20 \%$ \\
$\mathrm{SO}_{3}$ & $2.89 \%$ & $0.11 \%$ \\
\hline
\end{tabular}

I/II Portland cement and silica fume. Table 3 shows the physical properties of the coarse aggregate and the RCA. Information about the trial batches can be found in Section 3.2.

\subsection{Concrete Mixtures}

In order to develop a HSC mixture that used both local materials and RAC, three varying mixtures were developed to first produce a HSC baseline, once an optimum HSC mixture was reached a partial replacement of the coarse aggregate was replaced with RCA, completed in $10 \%, 20 \%$, and $30 \%$ increments. The literature has shown that an upper limit of $30 \%$ be used in order to maintain the standard requirement of $5 \%$ absorption capacity of aggregates for structural concrete [13] [14]. The literature has also shown that replacement percentages of approximately $15 \%$ - 40\% begin to diminish the strength of the concrete compared to the control mixture [6] [13] [14]. Therefore, three replacement percentages of $10 \%, 20 \%$, and $30 \%$ were selected for this study. Section 4 describes the results obtained from the trail mixtures and the recommended final RCA-HSC mixture. All trial mixtures were developed based off the recommendations of the literature [1]-[3] [13] [14] and off of data obtained from each trial. The individual trial mixtures were categorized as follows:

Trial A: The mixtures in this category used Type I/II Portland cement, HRWRA, and silica fume. The aggregate for trial group A was Limestone coarse aggregate with a top size of 1.18-mm (0.0469-in.) and manufactured sand with an approximate size range of $0.105-\mathrm{mm}-0.60-\mathrm{mm}(0.0059$-in. - 0.0232-in.). Three water-tocement ratios were investigated of $0.32,0.30$, and 0.28 .

Trial B: The mixtures in this category used Type I/II Portland cement, HRWRA, and silica fume. The aggregate for trial group B contained Dolomite coarse aggregate with a top size of 2.36-mm (0.093-in.) and Dolomite fine aggregate with an approximate size of $1.18-\mathrm{mm}(0.0469$-in.). Three water-to-cement ratios were investigated of $0.32,0.30$, and 0.28 .

Trial C: The mixtures in this category used Type I/II Portland cement, HRWRA, and silica fume. The aggregate for trial group $C$ consisted of Dolomite coarse aggregate with a top size of 1.18-mm (0.0469-in.) and manufactured sand with an approximate size range of 0.105-mm - 0.60-mm (0.0059-in. - 0.0232-in.). Three waterto-cement ratios were investigated of $0.32,0.30$, and 0.28 .

As shown in the three trial mixtures investigated, many of the mixture constituents were held constant in order to determine the impact of the local aggregates and aggregate size. Therefore, HRWRA, silica fume, and Type I/II cement were held constant and weighted based off of the literature. As the literature vastly differs on 
Table 3. Physical properties of coarse aggregate and RCA.

\begin{tabular}{cccccc}
\hline Property & Standard & Unit & Limestone Coarse Agg. & Dolomite Coarse Agg. & RCA \\
\hline Unit Weight & ASTM C29 & $\mathrm{kg} / \mathrm{m}^{3}\left(\mathrm{lb} / \mathrm{ft}^{3}\right)$ & $1442(90.0)$ & $1859(116.0)$ & $1411(88.0)$ \\
Water absorption & ASTM C127 & $\%$ & 2.98 & 3.19 & 4.12 \\
Bulk Specific Gravity ${ }_{\text {ssd }}{ }^{\mathrm{a}}$ & ASTM C127 & - & 2.57 & 2.72 & 2.42 \\
Bulk Specific Gravity $_{\text {od }}{ }^{\mathrm{b}}$ & ASTM C127 & - & 2.51 & 2.68 & 2.32
\end{tabular}

${ }^{\mathrm{a}}$ ssd, saturated surface dry condition; ${ }^{\mathrm{b}}$ od, oven dried condition.

the water-to-cement ratio, three ratios were investigated per trial batch. Due to this change, the HRWRA may vary slightly to maintain a consistent flow-ability/workability of the concrete. As the results will demonstrate, trail $\mathrm{C}$ produced the highest results with a w/c of 0.28 . Therefore, trial mixture $\mathrm{C}$ was used as the baseline HSC for coarse aggregate replacement of RCA. Table 4 displays the mixture proportions for all the trial batches and the RCA-HSC mixtures.

\subsection{Specimen Preparation}

The aggregate used in this study (coarse and fine) were sieved to obtain the desired size needed as described previously. The aggregates were then thoroughly washed over a No. 200 sieve to remove any fine dust or debris. After washing, the aggregates were oven dried at $44^{\circ} \mathrm{C}\left(110^{\circ} \mathrm{F}\right)$ to achieve a $0 \%$ moisture content.

The constituents of each mixture were then mixed for approximately 20 minutes using a laboratory pan mixer. The dry constituents (aggregate, cement, silica fume) were mixed for the first 2 minutes and then $75 \%$ of the water was added. After thorough mixing, the HRWRA was added with the remaining $25 \%$ of the water. This preparation method was used based off of the literature and experience [1]-[3] [13]-[16].

\subsection{Curing Regimens}

In order to minimize as many variables as possible, three curing regimens were investigated on the first mixture developed (Trial A - w/c = 0.32). Trial mixture A was selected to determine the impact of the curing regimen, as it was the first mixture designed and batched. For the first regimen, concrete specimens were cured at room temperature $\left(23^{\circ} \mathrm{C}\left[73^{\circ} \mathrm{F}\right]\right)$ for the first 24 hours. Once the specimens were demolded, they were moist cured at $23^{\circ} \mathrm{C}\left(73^{\circ} \mathrm{F}\right)$ and a relative humidity of $98 \%$ until the day of testing. This curing method is a traditional curing method for conventional concrete as outline in ASTM C192-15 [17]. For reporting purposes this curing method will be reported as Traditionally Cured (TC).

The second curing regimen consisted of curing the specimens at room temperature $23^{\circ} \mathrm{C}\left(73^{\circ} \mathrm{F}\right)$ for the first 24 hours. After the specimens were demolded, the specimens were heat cured in a water bath at a temperature of $50^{\circ} \mathrm{C}\left(122^{\circ} \mathrm{F}\right)$ until the time of testing. For reporting purposes this curing regimen will be reported as Heated Bath Cured (HBC).

The third curing regimen also cured the samples at room temperature $23^{\circ} \mathrm{C}\left(73^{\circ} \mathrm{F}\right)$ for the first 24 hours. After demolding, the specimens were heat cured in a water bath at $50^{\circ} \mathrm{C}\left(122^{\circ} \mathrm{F}\right)$ until 2 days prior to testing. At two days prior to testing, the specimens were removed from the water bath and dry cured at $200^{\circ} \mathrm{C}\left(392^{\circ} \mathrm{F}\right)$. For reporting purposes this curing method will be designated as Oven Dried Curing (ODC). The above curing regimens were developed based on the study by Shaheen (2006) et al. [18].

\subsection{Compression Testing}

Compressive strength specimens were molded using 50.8-mm (2-in.) cube molds. Cubes specimens were used to avoid problems with end preparation of cylindrical specimens [2]. After the specimens were properly cured they were individually tested according to BS 12390-3-2009 [19]. The British Standard was used as it provides greater detail to testing hardened concrete cubes in compression than ASTM C 39-15a [19] [20]. An average of three samples were tested per data point reported in the results section. Therefore, a minimum of nine specimens was produced per mixture per w/c in order to obtain a reportable value. Trail mixture A required additional samples as this was the mixture that was used to investigate the curing regimen. 


\section{Results and Discussion}

\subsection{Curing Regimen}

The curing regimen results are discussed first as the curing variable was determined prior to curing the majority of the specimens. The first mixture listed in Table 4 (Trial A $-\mathrm{w} / \mathrm{c}=0.32$ ) was used as the baseline mixture to determine the impact of the curing regimen. Therefore enough specimens were prepared using the batch quantities for this mixture in order to determine the affect of the three curing regimens as outlined above. Figure 1 shows the results of the three curing methods on Trial $\mathrm{A}-\mathrm{w} / \mathrm{c}=0.32$ ).

As seen in Figure 1, the curing regimen significantly influenced the compressive strength of the HSC. The specimens that were cured using the traditional curing method resulted in the lowest average strengths. This is expected as the literature suggests that water curing, such as "full immersion" curing is required for water-to-cement ratios below 0.40 [2]. This is due to the degree of hydration being significantly reduced due to less water in the mixture, therefore it is beneficial to fully immerse the specimens during curing to support additional hydration [2]. Specimens that were cured using the hot bath curing method demonstrated an increase in strength versus the traditional curing method. This curing regimen not only provided a full immersion curing method, but

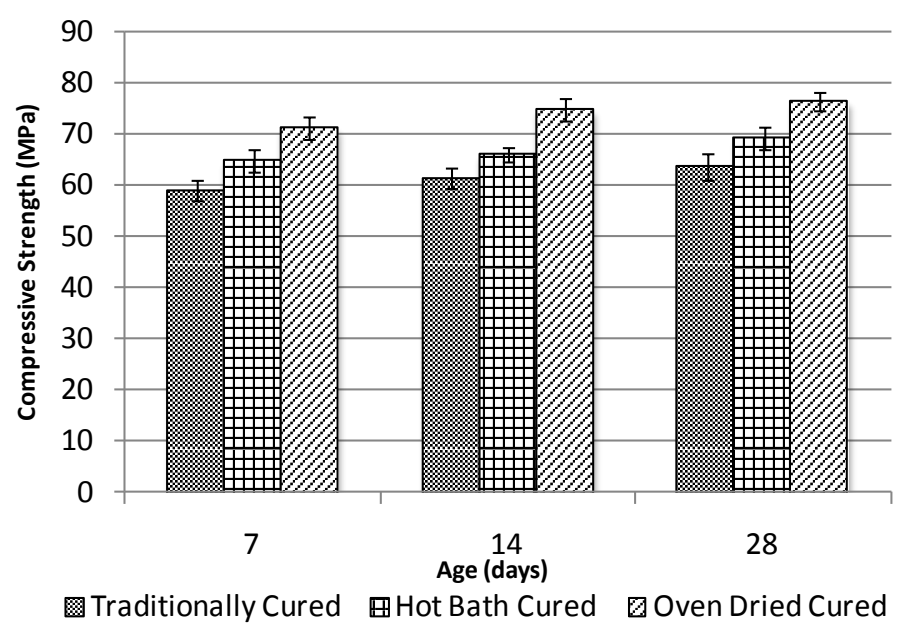

Figure 1. Impact of curing regimen on the compressive strength of Trial $\mathrm{A}-\mathrm{w} / \mathrm{c}=0.32$ at varying ages.

Table 4. Mixture proportions of the trail mixtures and RCA-HSC $-\mathrm{kg} / \mathrm{m}^{3}\left(\mathrm{lb} / \mathrm{yd}^{3}\right)$.

\begin{tabular}{|c|c|c|c|c|c|c|c|c|}
\hline Mixture Name & $\mathrm{w} / \mathrm{c}$ & Cement & $\begin{array}{l}\text { Silica } \\
\text { Fume }\end{array}$ & $\begin{array}{l}\text { Coarse } \\
\text { Aggregate }\end{array}$ & $\begin{array}{c}\text { Fine } \\
\text { Aggregate }\end{array}$ & RCA & Water & HRWRA \\
\hline \multirow{4}{*}{ Trial A } & 0.32 & & & & & & $166(280)$ & $16(27)$ \\
\hline & 0.3 & $520(876)$ & 100 (69) & 825 (1391) & 685 (1155) & N/A & $156(263)$ & $18(30)$ \\
\hline & 0.28 & & & & & & $145(244)$ & $20(34)$ \\
\hline & 0.32 & & & & & & $166(280)$ & $16(27)$ \\
\hline \multirow[t]{3}{*}{ Trial B } & 0.3 & $520(876)$ & 100 (69) & 825 (1391) & 685 (1155) & N/A & 156 (263) & $18(30)$ \\
\hline & 0.28 & & & & & & $145(244)$ & $20(34)$ \\
\hline & 0.32 & & & & & & $166(280)$ & $16(27)$ \\
\hline \multirow[t]{2}{*}{ Trial C } & 0.3 & $520(876)$ & 100 (69) & 825 (1391) & 685 (1155) & N/A & 156 (263) & $18(30)$ \\
\hline & 0.28 & & & & & & 145 (244) & $20(34)$ \\
\hline RCA-HSC-10 & & & & 742.5 (1252) & & 82.5 (139) & & $16(27)$ \\
\hline RCA-HSC-20 & 0.28 & $520(876)$ & 100 (69) & $660(1112)$ & 685 (1155) & 165 (278) & $145(244)$ & $18(30)$ \\
\hline RCA-HSC-30 & & & & 577.5 (973) & & 247.5 (417) & & $20(34)$ \\
\hline
\end{tabular}


also an increase in curing temperature as the water was held at $50^{\circ} \mathrm{C}\left(122^{\circ} \mathrm{F}\right)$. This form of curing has being used by many authors in order to promote extra hydrates and develop higher early strengths [5]-[8] [12]. This curing regimen resulted in an average $7.3 \%$ increase in compressive strength over the traditional curing method. The last curing method, oven dried curing, which utilized a heated water bath and an oven for the last two days prior to testing produced the highest compressive strengths. The oven dried curing resulted in an average $18.8 \%$ increase over the traditional curing method and an average $10.5 \%$ increase over the hot bath cured. This increase of compressive strength is attributed to acceleration of the hydration reaction when the specimens were kept in the water bath and the formation of secondary calcium silicate hydrate (CSH) from the pozzolanic reaction of the silica fume when the specimens were kept in the oven at $200^{\circ} \mathrm{C}\left(392^{\circ} \mathrm{F}\right)$ for two days prior to testing. These results are consistent with similar results as observed from the literature [5]-[8] [12]. To determine if there is a statistical difference between the three curing regimens a sample t-test was performed. The test was performed with a 95\% confidence level and the statistical significance (p value) considered at 0.05 level of confidence was used to analyze the data. All $\mathrm{p}$ values recorded were less than 0.05 ; therefore there is a difference between each curing method. Based off the observation of the curing regimen, all specimens prepared and discussed in the results section have been cured utilizing the oven dried curing regimen.

\subsection{Impact of the Water-to-Cement Ratio}

The next variable that was investigated in the development of a sustainable HSC mixture was the water-tocement ratio (w/c). It has been well documented that a lower w/c results in a higher strength concrete and for HSC the w/c should be lower than 0.4 [2]. As previously stated, three w/c ratios were investigated for this study, which are $0.32,0.30$, and 0.28 . Figure 2 shows the impact of the w/c on the compressive strength of the specimens from Trial batches A-C.

As shown in Figure 2, the w/c has a significant impact on the strength of the three trial HSC mixtures. Although, the three w/c are only separated by two tenths, the impact is significant in such a controlled mixture as HSC. All three trial batches show that the highest strength occurs at a w/c of 0.28 , which is the lowest tested for this study. This is also the case for the age of the HSC. These results are similar to w/c as presented in the literature [5]-[8] [12]. Due to the tight control of these mixtures, the average standard deviation for all three trials at each age was approximately 2.16. A t-test was also completed for the impact of the w/c ratio, which also revealed a difference between each grouping. Therefore, the w/c in fact has an impact on the developed mixtures, as is expected based off the literature and experience. Figure 2 also compares the range of the three trial mixtures; such that Trial C demonstrates the highest recorded compressive strengths. Based off of these results a w/c of 0.28 was selected for the RCA-HSC. These results and results for each trial batch at this w/c are presented in subsequent sections.

\subsection{Effect of RCA}

The compressive strength was investigated for all trial batches and RCA-HSC specimens produced. To investigate the repeatability of the compressive strengths of these mixtures, testing was conducted on three specimens cast from each of the batches. As previously mentioned the compressive strengths were measured at 7, 14, and 28 days and 50.8-mm (2-in.) cubes were used. To facilitate a better coating of cement paste over the aggregate
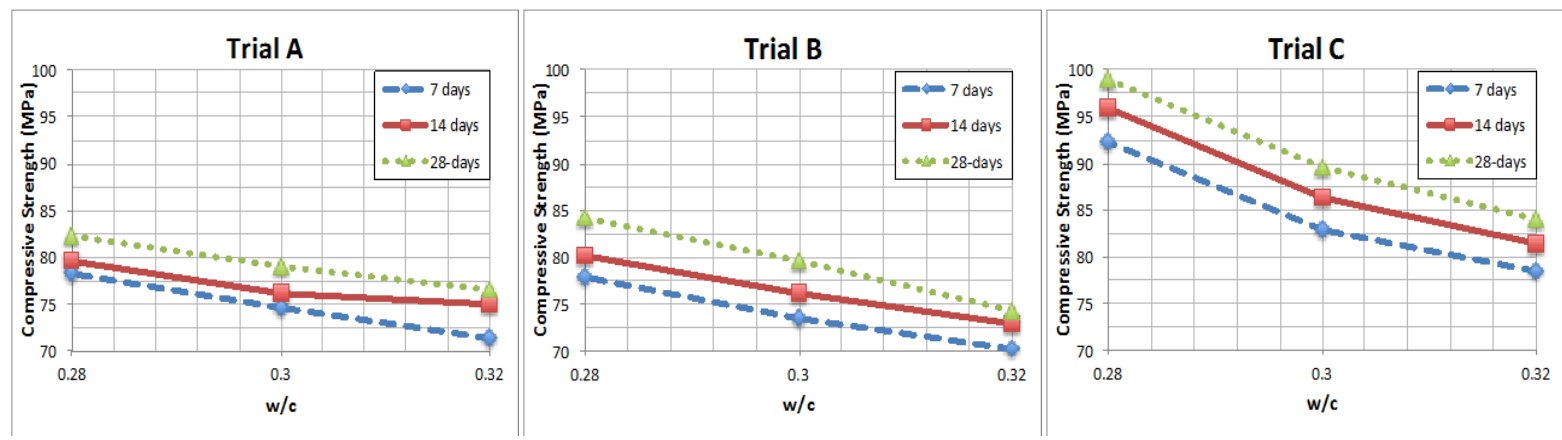

Figure 2. Impact of w/c on the compressive strength of HSC. 
particles and increase the compressive strength, the dust was removed by washing the aggregates over a No. 200 sieve. The average compressive strengths of the trial mixtures can be seen in Figure 3.

Figure 3 demonstrates the impact of age versus the strength of the three trial HSC mixtures. Recall that all of these samples have a consistent w/c of 0.28 and are all cured using the oven dried curing regimen. As expected, the average compressive strength increases in strength as the concrete ages. Additionally, the average standard deviation for this data set was approximately 2.20 due to the tight control of the mixtures. Comparing the three trial mixtures reveals that Trial $\mathrm{C}$ produces the highest overall compressive strengths at every age. Trial $\mathrm{C}$ has an average percent increase of $25 \%$ versus the average compressive strengths of Trial A. Comparing Trials B and A demonstrates an average increase in compressive strength from B to A of only $5 \%$. The increase in strength is due to the size and type of aggregate used. Trial A utilizes limestone coarse aggregate and manufactured sand that is produced from crushed limestone. Limestone is known to be a moderately strong aggregate, but is most commonly used in concrete construction due to it being readily available [21]. Dolomite aggregate was used in Trials B and C and it was selected as it's also readily available in central Texas, but it has a slightly higher density and strength compared to limestone [22]. However, Trial C uses both dolomite as a coarse aggregate and manufactured (limestone) sand as a fine aggregate. This was done due to the higher density of dolomite and the results obtained by Aquino et al. (2010) which shows that fine limestone, such as manufactured sand is known to improve the strength of concrete [21]. Therefore, Trial C combines the impact of both types of locally available aggregates. It is understood that a secondary cause of the minimal increase in strength from trial A to B was due to the size of the aggregates. The smallest aggregate used in Trial B was 1.18-mm (0.0469-in.), which was the largest aggregate size used in both Trials A and C. It should also be noted that all of the strengths at each age and from each trial were higher than $70 \mathrm{MPa}(10,150 \mathrm{psi})$, which is above the range for consideration as HSC. The highest reported strength was from Trial C at a 28-day strength of 98.9 MPa (14,344 psi). Since Trial C had the highest performance, it was selected as the mixture to be used with the RCA replacement. Based off the literature, RCA replacement percentages for coarse aggregates should be less than or equal to $30 \%$ replacement by mass, therefore three replacement percentages were selected of $30 \%, 20 \%$, and $10 \%$. The compressive strength verses age for the RCA-HSC mixtures can be seen in Figure 4.

Figure 4 displays the compressive strength results for the developed sustainable high strength concrete using RCA and local materials. Trial C compressive strength data was included in this plot for comparison as this mixture was the baseline for all RCA-HSC mixtures. The results ultimately show a decrease in strength by including any percent replacement percentage investigated in this study. The decrease in strength increased with an increase in percentage of RCA used, i.e. the highest strength loss came from the $30 \%$ replacement of RCA coarse aggregate. The average strength loss was $7.9 \%, 14.4 \%$, and $22.6 \%$ for the $10 \%, 20 \%$, and $30 \%$ RCA inclusion respectively and an average standard deviation for each grouping of 2.63. This decrease in compressive strength is typical for most concrete mixtures containing RCA, as the quality of the RCA aggregate is significantly lower than virgin aggregates [5]-[8] [12]. The major issue when dealing with RCA is the fact that the

\section{Trial HSC Mixtures $(w / c=0.28)$}

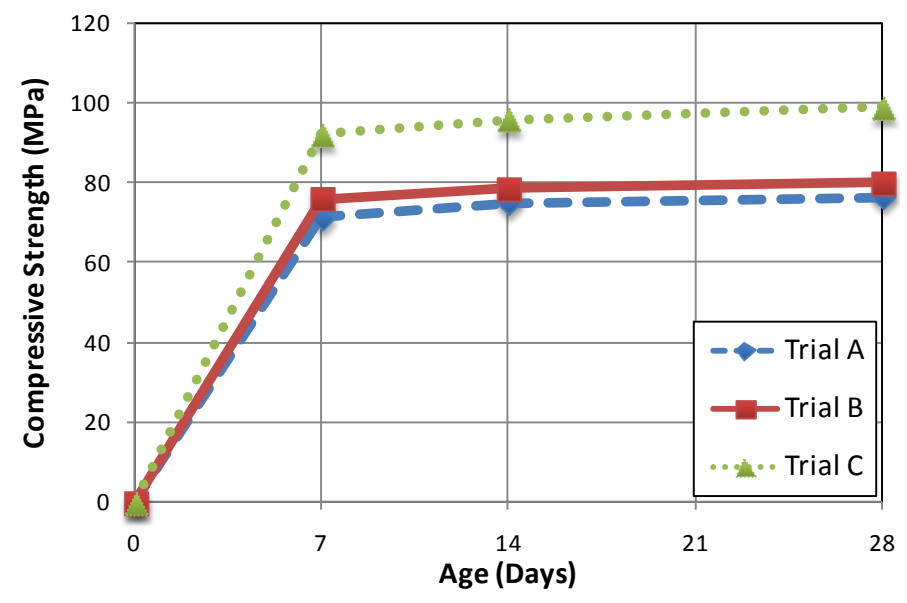

Figure 3. Average compressive strength of the trial HSC mixtures. 


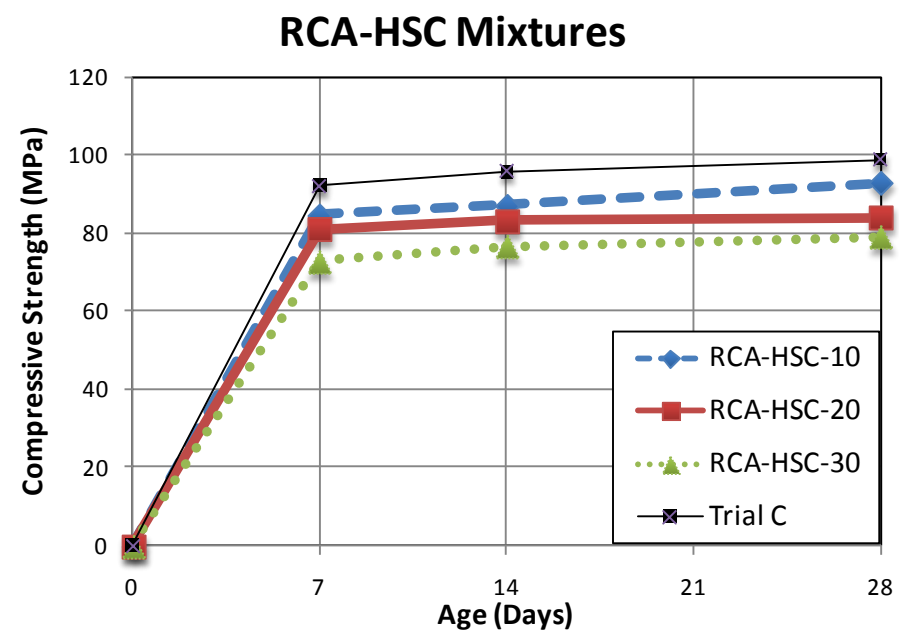

Figure 4. Average compressive strength of the RCA-HSC mixtures.

aggregate type and condition is unknown. Additionally, it is often difficult to remove debris or foreign matter that could be embedded in the RCA that could affect the performance of the new concrete. Although, there is a minor reduction in strength when using RCA as partial coarse aggregate replacement in HSC, it should be noted that the lowest recorded strength from RCA-HSC-30 was $79.1 \mathrm{MPa}(11,476 \mathrm{psi})$ at 28-days. This strength is still high enough to be considered HSC and is also approximately the same strength at 28-days of the Trial B mixture that contained no RCA elements. A drop in strength was expected based off the literature; therefore the highest performing trial mixture was selected such that the novel sustainable construction building material would still have a high strength.

\section{Conclusion}

A novel sustainable construction building material has been developed that has high strength, uses recycled elements, and all the constituents were obtained locally. This study focused on developing a novel construction building material that can impact the sustainable construction building movement by not only developing a HSC, but the HSC has been made more sustainable by utilizing RCA and all local constituents. This study focused on maintaining consistent variables in order to assess the impact of the RCA on the HSC. This was developed by first assessing the impact of the curing regime on the strength of the concrete. Three regimens were investigated, which were cultivated based off the literature. Once an optimum curing regimen was reached, the w/c ratio was investigated. Again three different w/c ratios were investigated, which were also selected based off the literature. After the optimum curing regimen and w/c ratio was obtained, three different mixture designs were developed and compared. The three mixture designs consisted of two different locally available aggregate types and the size of the aggregate. The compressive strength measurements were compared at three testing ages of 7,14 , and 28 days. The highest performing HSC mixture was then used to investigate the impact of the RCA. RCA was used to partially replace the coarse aggregate in the top performing trial mixture at $10 \%, 20 \%$ and $30 \%$ replacement by mass. The results show that the RCA-HSC had a low end strength of $72.9 \mathrm{MPa}(10,576 \mathrm{psi})$ at 7 days from the 30\% RCA replacement and a high end strength of $93.0 \mathrm{MPa}(13,484 \mathrm{psi})$ at 28 days from the $10 \%$ RCA replacement. Therefore, a novel sustainable HSC mixture has been produced that utilizes $100 \%$ local materials.

\section{References}

[1] Andrzej, A and Alina, K (2002) Influence of Recycled Aggregates on Mechanical Properties of HS/HPC. Cement and Concrete Composites, 24, 269-279. http://dx.doi.org/10.1016/S0958-9465(01)00012-9

[2] ACI Committee 363 (2010) Report on High-Strength Concrete. ACI 363R-10, American Concrete Institute Committee 363, Farmington Hills, MI.

[3] Dili, A.S. and Santhanam, M. (2004) Investigations on Reactive Powder Concrete: A Developing Ultra High Strength Technology. The Indian Concrete Journal, 74, 33-38. 
[4] Azhar, S., Carlton, W.A., Olsen, D. and Ahmad, I. (2011) Building Information Modeling for Sustainable Design and LEED® Rating Analysis. Automation in Construction, 20, 217-224. http://dx.doi.org/10.1016/j.autcon.2010.09.019.

[5] Rahal, K. (2007) Mechanical Properties of Concrete with Recycled Coarse Aggregate. Building and Environment, 42, 407-415. http://dx.doi.org/10.1016/j.buildenv.2005.07.033

[6] Buck, A.D. (1977) Recycled Concrete as a Source of Aggregate. ACI Journal, 74, 212-219.

[7] Hansen, T.C. and Narud, H. (1983) Strength of Recycled Concrete Made from Crushed Concrete Coarse Aggregate. Concrete International, 1, 79-83.

[8] Forster, S.W. (1986) Recycled Concrete as Aggregate. Concrete International, 8, 34-40.

[9] Ravindraraj, R.S., Steward, M. and Greco, D. (2000) Variability of Recycled Concrete Aggregate and Its Effect on Concrete Properties-A Case Study in Australia. International Workshop on Recycled Concrete, JSPS 76 Committee on Construction Materials, Tokyo, September 2000, 27-42.

[10] Yamato, T., Emoto, Y. and Soeda, M. (1998) Mechanical Properties, Drying Shrinkage and Resistance to Freezing and Thawing of Concrete Using Recycled Aggregate. ACI Special Publication SP 179-7, American Concrete Institute, Farmington Hills, MI, 105-121.

[11] Gerardu, J.J.A. and Hendriks, D.F. (1985) Recycling of Road Pavement Materials in the Netherlands. Rijkswaterstaat Communications No. 38, The Hague.

[12] Frondistou-Yannas, S. (1977) Waste Concrete as Aggregate for New Concrete. ACI Journal, 78, 373-376.

[13] Ajdukiewicz, A. and Kliszczewicz, A. (2002) Influence of Recycled Aggregates on Mechanical Properties of HS/HPC. Cement and Concrete Composites, 24, 269-279. http://dx.doi.org/10.1016/S0958-9465(01)00012-9

[14] Tu, T.-Y., Chen, Y.-Y. and Hwang, C.-L. (2006) Properties of HPC with Recycled Aggregates. Cement and Concrete Research, 36, 943-950. http://dx.doi.org/10.1016/j.cemconres.2005.11.022

[15] Rao, A., Jha, K.N. and Misra, S. (2007) Use of Aggregates from Recycled Construction and Demolition Waste in Concrete. Resources, Conservation and Recycling, 50, 71-81. http://dx.doi.org/10.1016/j.resconrec.2006.05.010.

[16] Evangelista, L. and de Brito, J. (2007) Mechanical Behaviour of Concrete Made with Fine Recycled Concrete Aggregates. Cement and Concrete Composites, 29, 397-401. http://dx.doi.org/10.1016/j.cemconcomp.2006.12.004.

[17] ASTM Standard C192-15 (2015) Standard Practice for Making and Curing Concrete Test Specimens in the Laboratory. ASTM International, West Conshohocken, PA. www.astm.org

[18] Shaheen, E. and Shrive, N.J. (2006) Optimization of Mechanical Properties and Durability of Reactive Powder Concrete. ACI Materials Journal, 103, 444-451.

[19] BS EN 12390-3:2009 (2009) Testing Hardened Concrete Compressive Strength of Test Specimens B/517/1, 22.

[20] ASTM Standard C 39-15a (2015) Standard Test Method for Compressive Strength of Cylindrical Concrete Specimens. ASTM International, West Conshohocken, PA. www.astm.org

[21] Aquino, C., Inoue, M., Miura, H., Mizuta, M. and Okamoto, T. (2010) The Effects of Limestone Aggregate on Concrete Properties. Construction and Building Materials, 24, 2363-2368. http://dx.doi.org/10.1016/j.conbuildmat.2010.05.008

[22] Mikhailova, O., Yakovlev, G., Maeva, I. and Senkov, S. (2013) Effect of Dolomite Limestone Powder on the Compressive Strength of Concrete. Procedia Engineering, 57, 775-780. http://dx.doi.org/10.1016/j.proeng.2013.04.098 